\title{
Deteriorating microbiomes in agriculture - the unintended effects of pesticides on microbial life
}

\author{
Brendan A. Daisley ${ }^{1,2}$, Anna M. Chernyshova ${ }^{1}$, Graham J. Thompson ${ }^{1}$, Emma Allen-Vercoe ${ }^{2}$ \\ 'Department of Biology, Western University, London, ON N6A 5C1, Canada. \\ ${ }^{2}$ Department of Molecular and Cellular Biology, University of Guelph, Guelph, ON N1G 2W1, Canada.
}

Correspondence to: Dr. Emma Allen-Vercoe, Department of Molecular and Cellular Biology, University of Guelph, 50 Stone Road East, Guelph, ON N1G 2W1, Canada. E-mail: eav@uoguelph.ca

How to cite this article: Daisley BA, Chernyshova AM, Thompson GJ, Allen-Vercoe E. Deteriorating microbiomes in agriculture the unintended effects of pesticides on microbial life. Microbiome Res Rep 2022;1:6. https://dx.doi.org/10.20517/mrr.2021.08

Received:1 Dec 2021 First Decision: 10 Jan 2022 Revised: 12 Jan 2022 Accepted: 21 Jan 2022 Published: 25 Jan 2022

Academic Editor: Marco Ventura Copy Editor: Xi-Jun Chen Production Editor: Xi-Jun Chen

\begin{abstract}
There is emerging concern regarding the unintentional and often unrecognized antimicrobial properties of "nonantimicrobial" pesticides. This includes insecticides, herbicides, and fungicides commonly used in agriculture that are known to produce broad ranging, off-target effects on beneficial wildlife, even at seemingly non-toxic low dose exposures. Notably, these obscure adverse interactions may be related to host-associated microbiome damage occurring from antimicrobial effects, rather than the presumed toxic effects of pesticides on host tissue. Here, we critically review the literature on this topic as it pertains to the rhizosphere microbiome of crop plants and gut microbiome of pollinator insects (namely managed populations of the western honey bee, Apis mellifera), since both are frequent recipients of chronic pesticide exposure. Clear linkages between pesticide mode of action and host-specific microbiome functionalities are identified in relation to potential antimicrobial risks. For example, inherent differences in nitrogen metabolism of plant- and insect-associated microbiomes may dictate whether neonicotinoid-based insecticides ultimately exert antimicrobial activities or not. Several other context-dependent scenarios are discussed. In addition to direct effects (e.g., microbicidal action of the parent compound or breakdown metabolites), pesticides may indirectly alter the trajectory of host-microbiome coevolution in honey bees via modulation of social behaviours and the insect gut-brain axis - conceivably with consequences on plantpollinator symbiosis as well. In summary, current evidence suggests: (1) immediate action is needed by regulatory authorities in amending safety assessments for "non-antimicrobial" pesticides; and (2) that the development of host-free microbiome model systems could be useful for rapidly screening pesticides against functionally distinct microbial catalogues of interest.
\end{abstract}


Keywords: Microbiome, host-microbe interactions, agriculture, pesticides, microbial evolution, microbe-xenobiotic interactions, bioremediation, environmental sustainability

\section{INTRODUCTION}

Arguably, there is a microbial component inherent to all known systems on Earth with cumulative evidence supporting that niche-adapted microbial communities play unequivocally important roles in total ecosystem functioning ${ }^{[1]}$. This includes, but is not limited to, the facilitation of marine and atmospheric biogeochemical processes, regulation of soil-plant nutrient cycling, and maintenance of healthy animal communities. Emerging ideologies such as "Planetary Health" and "OneHealth" emphasize these fundamental roles of microbial metabolic processes in supporting macroscopic reality at the systems-level, and further suggest that microorganisms should be viewed as unified constituents rather than as separate entities, as they have been historically regarded ${ }^{[2,3]}$.

Consistent with these schemas is the holobiont (or hologenome) theory of evolution ${ }^{[4]}$ which posits that host-microbe co-adaptation has driven functional interdependence between many animal species and their gut microbiomes (i.e., referring to the community of microorganisms residing in the intestinal tract as well as their collective metabolic potential). Exemplifying this interdependence, animal species frequently rely on their gut microbiomes for nutrition, pathogen exclusion, and immunomodulatory function $s^{[5]}$. The human gut microbiome has been well characterized in this regard, although there is substantial evidence from insect species too - including the western honey bee (Apis mellifera). In particular, this eusocial insect species relies heavily on the bacterial members of its gut microbiota as a result of depauperate immune and detoxification gene repertoires ${ }^{[6]}$. Similar relationships exist between plant hosts and the microbe-dense soil zone surrounding plant roots, known as the rhizosphere (or "microbe storehouse"), that plays a multifunctional role in supporting plant growth and is a critical factor influencing crop yields in agriculture $^{[7]}$. The functional similarities between the gut microbiome of animals and the rhizosphere microbiome of plants have been discussed previously ${ }^{[8]}$, as has the related theory of "the host microbiome as an ecosystem on a leash" ${ }^{[0]}$.

Here, we draw attention to the neglected fact that anthropogenic activities (primarily those over the past century relating to farming practices) have introduced an astonishing number of pesticides and other agrochemical xenobiotics into the environment ( 90,000 active products registered in the NPIRS database alone ${ }^{[10]}$ ), and that many can exert unintentional antimicrobial activities that disrupt host-microbiome homeostasis ${ }^{[11]}$. These activities include the microbicidal or microbiostatic properties exhibited by various herbicides, insecticides, and fungicides, which together constitute over $95 \%$ of all pesticides used worldwide $^{[12]}$. To note, these effects are often unforeseen (e.g., insecticides - by design - target insects, not microbes) and are not adequately monitored by regulatory agencies since most pesticides are classified as "non-antimicrobial" chemicals. It is thus conceivable that widespread extinction of plant and animal hostadapted microbes may already be occurring, undetected, as a result of chronic sub-lethal pesticide exposures (i.e., through the use of compounds deemed non-toxic to the physiology of off-target host species, but not necessarily their microbiomes). Nonetheless, it is difficult to ascertain the extent of damage, since baseline host-associated microbiome data is often lacking.

We can gain some insight into the long-term consequences of microbiome damage from industrialized human societies that have undergone a systematic depletion in host-adapted microbes due to transgenerational antibiotic exposure (i.e., missing microbe hypothesis ${ }^{[13]}$ ) and excessive use of disinfectants (i.e., hygiene hypothesis of disease $\left.\mathrm{e}^{[14]}\right)$. Importantly, these reductions in microbial diversity are directly 
associated with altered functionality of the gut microbiome, and are thought to represent a major instigating factor behind the growing global epidemic of chronic, non-communicable, metabolic disease ${ }^{[15]}$. Such metabolic disorders include irritable bowel syndrome ${ }^{[16]}$, type-2 diabetes ${ }^{[17]}$, obesity ${ }^{[18]}$, atherosclerosis ${ }^{[19]}$, and several types of cancer ${ }^{[20]}$. Thus, while the use of antibiotics and disinfectants have undoubtedly revolutionized clinical healthcare and tremendously reduced the spread and lethality of infectious diseases, persistent exposure to antimicrobial agents may pose significant long-term health complications.

An analogous scenario could be the case for the effects of pesticides, which have revolutionized the agricultural industry (e.g., through minimizing crop loss to pest species) but may pose serious risks to wildlife metabolic health and long-term environmental sustainability. Previous reports have exhaustively described the consequential physiological effects of pesticides on off-target plant and animal tissue ${ }^{[21-24]}$. In this review, we detail the current knowledge relating to the important non-canonical mechanisms by which certain pesticides can obstruct plant and pollinator health via off-target interactions with the host microbiome [Figure 1]. Specific attention will be given to managed western honey bees (A. mellifera) on the basis of their proclivity to encounter pesticides, their unsustainable colony loss over the past decade, and their importance to agriculture and global food security.

\section{THE REGULATORY DILEMMA OF “NON-ANTIMICROBIAL” PESTICIDES}

The Environmental Protection Agency (EPA) of the United States broadly classifies pesticides to be any chemical compound utilized for the purpose of killing crop pests that interfere with agricultural production - most commonly referring to that of herbicides, insecticides, and fungicides. A longstanding issue surrounding the use of pesticides, however, is the off-target deleterious effects they can have on a broad range of species found in terrestrial and aquatic ecosystems. In efforts to make sound regulatory judgements about these risks, authoritative bodies worldwide have attempted to implement minimum data and safety information requirements in relation to a given pesticide product's potential for causing unreasonable adverse effects. For example, the EPA's regulation "Data Requirements for Registration" (issued in 1984 under title 40, part 158 of the Code of Federal Regulations) specifies that risk assessments for the registration of new pesticides must evaluate the Ecological Risks, Human Health Risks, and Environmental Accumulation Risks ${ }^{[25]}$. It is important to note, however, that compliance with regard to ecological assessments extends only to "non-target plants, fish, and wildlife species" without any legislative guidance provided for microorganisms.

Only recently in 2013 did the EPA promulgate the final rules on data requirements (revised part $158 \mathrm{~W}$ ) to provide distinct jurisdiction for "antimicrobial" and "non-antimicrobial" pesticides under the Federal Insecticide, Fungicide, and Rodenticide Act (FIFRA). Many pesticides with potential antimicrobial properties are nonetheless still registered as "non-antimicrobial" products (and are thus regulated under conventional mandates) as the result of mutually exclusive categorization schemas and a long list of exemptions. For example, an "antimicrobial pesticide" is defined under section $2(\mathrm{~mm})$ of FIFRA as any pesticide designed to disinfect, sanitize, reduce, or mitigate the growth of bacteria, viruses, fungi, protozoa, algae, or slime mold $^{[26]}$. In nearly all cases, though, these criteria are nullified by the presence of additional claims (e.g., herbicidal or insecticidal properties), which result in the product (e.g., herbicides and insecticides) being classified as a "non-antimicrobial pesticide". Perplexingly, agricultural fungicides are also considered a type of "non-antimicrobial pesticide" despite their registered intent as antimicrobial chemicals targeting fungal species. Legislative loopholes in classification such as these present a major concern as they obscure scientific communication and largely ignore the potential health hazards that common agrochemicals pose on plants and animals through interactions with their host-associated microbial communities. 


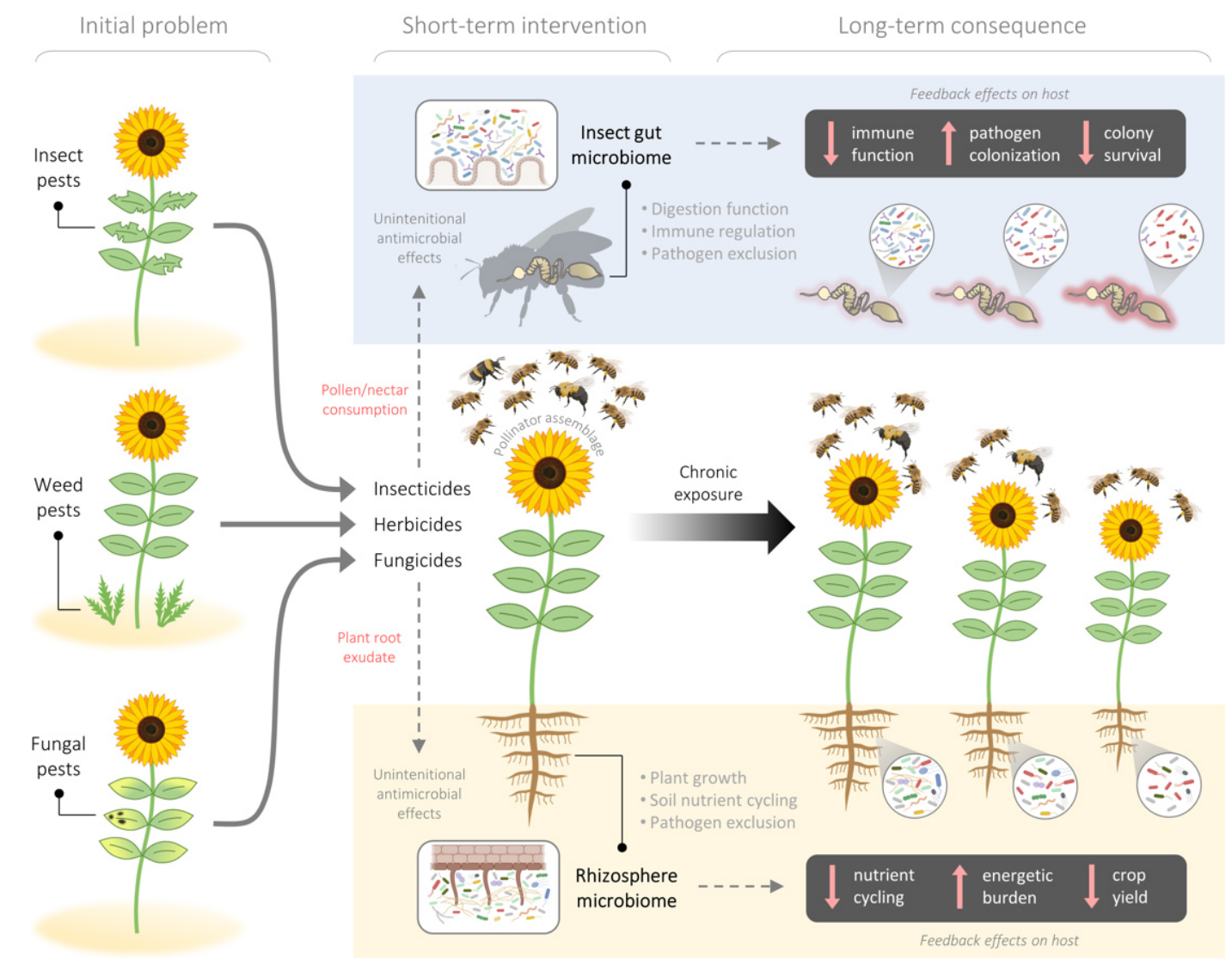

Figure 1. Schematic diagram illustrating pesticide-mediated microbiome effects on plants and insect pollinators. Insecticides, herbicides, and fungicides are commonly used to prevent crop diseases and minimize interference of crop pests in agriculture. These chemicals are widely popular for their perceptible benefits to crop health and yields over the short term. However, their unintentional antimicrobial effects can deteriorate the health-promoting microbial communities associated with plants and pollinators via chronic exposure through plant root exudate and pollen consumption, respectively. Ultimately, the feedback effects on host species have the potential to reduce long-term crop yields (via depletion of plant-growth promoting symbionts) and bee populations (via depletion of immune-regulating and pathogen excluding symbionts).

\section{DISENTANGLING HOW PESTICIDES DAMAGE HOST MICROBIOMES}

It is foreseeable that any chemical, in great enough quantity, could impede cellular biological function. Thus, the peak concentration and type of exposure (e.g., acute or chronic), as well as dose-dependent effects, are important considerations when evaluating the off-target antimicrobial effects of pesticides. Discussion in this review will accordingly focus on the antimicrobial mechanisms of insecticides, herbicides, and fungicides at environmentally realistic exposures. A brief in-text summary is provided for each of the relevant mechanisms shown in Figure 2, whereas a list of known interactions is reported in Table 1.

\section{Direct antimicrobial effects and lessons learned from legacy insecticides}

The bulk of pesticide applications almost invariably reaches the soil, facilitating direct interaction with soil microbes [Figure 2A]. As a result of this intuitive linkage, some of the earliest evidence of pesticides exhibiting antimicrobial properties comes from studies on the soil microbiome and legacy organochlorine (OCL) insecticides. By design, OCLs target the nervous system of insects by binding to the $\mathrm{GABA}_{\mathrm{A}}$ site of the gamma-aminobutyric acid (GABA) chloride ionophore complex, which ultimately causes paralysis and/or death via dysregulation of nerve cell membrane polarization. GABA is notably the most common inhibitory neurotransmitter in both vertebrate and invertebrate systems, and is especially crucial to honey bee foraging and grooming ${ }^{[45]}$. In situ investigations on OCLs demonstrate they can also have strong 
Table 1. Antimicrobial effects of common pesticides on plant- and pollinator-associated microbiomes

\begin{tabular}{|c|c|c|c|c|}
\hline $\begin{array}{l}\text { Pesticide } \\
\text { class }\end{array}$ & Pesticide name & Host & Effect on host-associated microbiome & Ref \\
\hline \multirow[t]{11}{*}{ Insecticides } & Heptachlor & Plants & $\begin{array}{l}\text { Growth inhibition for } \sim 92 \% \text { of Gram-positive strains tested with no effect on } \\
\text { any Gram-negative strains tested }\end{array}$ & [27] \\
\hline & DDT & Plants & $\begin{array}{l}\text { Decrease in active soil bacterial biomass by } \sim 60 \% \text { and an increase in fungal } \\
\text { biomass by } \sim 93 \%\end{array}$ & [28] \\
\hline & Carbaryl & Bees & $\begin{array}{l}\text { Decreased total gut bacterial loads by } ~ 90 \% \text { (enumerated via qPCR) } \\
\text { alongside a compositional depletion of Orbales at the order level }\end{array}$ & [29] \\
\hline & Clothianidin & Bees & $\begin{array}{l}\text { Gut region-specific signatures of dysbiosis in bacterial communities after } 28 \text { - } \\
\text { day exposure }\end{array}$ & [30] \\
\hline & \multirow[t]{4}{*}{ Imidacloprid } & Bees & $\begin{array}{l}\text { No effect on honey bee gut microbiota after } 5 \text {-day of exposure and no effect } \\
\text { on the growth of } 16 \text { honey bee-derived bacterial strains in pure culture }\end{array}$ & {$[31]$} \\
\hline & & Plants & $\begin{array}{l}\text { Species-specific inhibition of ammonia-oxidizing archaea and ammonia- } \\
\text { oxidizing bacteria }\end{array}$ & [32] \\
\hline & & Plants & $\begin{array}{l}\text { Dose- and duration-dependent effects on diversity metrics of rice crop } \\
\text { rhizosphere microbiome }\end{array}$ & [33] \\
\hline & & Plants & $\begin{array}{l}\text { Reduction in culturable fungi by } \sim 37 \% \text {, coupled with the decrease in } \beta \text { - } \\
\text { glycosidase, fluorescein diacetate hydrolase, acid phosphatase and urease } \\
\text { enzymatic activities }\end{array}$ & [33] \\
\hline & Imidacloprid and thiacloprid & Bees & $\begin{array}{l}\text { Time-dependent effects on bacterial and fungal alpha diversity in honey bees } \\
\text { during 35-day exposure }\end{array}$ & [34] \\
\hline & Thiacloprid & Plants & $\begin{array}{l}\text { Thiacloprid degradation by } \mathrm{N}_{2} \text {-fixing bacterium Microvirga flocculans produces } \\
\text { breakdown metabolites that feedback to inhibit the growth }\end{array}$ & [35] \\
\hline & Nitenpyram & Bees & $\begin{array}{l}\text { Near-complete clearance of the symbiont Gillimella spp. in honey bees after } \\
\text { 14-day exposure }\end{array}$ & [36] \\
\hline \multirow[t]{4}{*}{ Herbicide } & 2,4-Dichlorophenoxyacetic acid & Plants & $\begin{array}{l}\text { Reduction of nod gene expression by } 32 \% \text { in Sinorhizobium meliloti, ultimately } \\
\text { affecting nitrogen fixation and plant hormone signaling }\end{array}$ & [37] \\
\hline & Atrazine & Plants & $\begin{array}{l}\text { Inhibited germination and } ~ 80 \% \text { reduction in radial growth of fungal } \\
\text { symbiont Trichoderma atroviride }\end{array}$ & [38] \\
\hline & Glyphosate & Bees & $\begin{array}{l}\text { Reduction of symbiotic Snodgrassella alvi alongside the concurrent rise of } \\
\text { entomopathogenic Serratia marcescens in honey bees }\end{array}$ & [39] \\
\hline & Glyphosate & Plants & Increased prevalence of root-rot inducing Fusarium spp. & {$[40]$} \\
\hline \multirow[t]{4}{*}{ Fungicides } & $\begin{array}{l}\text { Carbendazim and } \\
\text { Hexaconazole }\end{array}$ & Plants & Dose-dependent inhibition of plant-growth promoting Pseudomonas spp. & [41] \\
\hline & $\begin{array}{l}\text { Azoxystrobin and } \\
\text { Chlorothalonil }\end{array}$ & Plants & $\begin{array}{l}\text { Inhibited radial growth on agar by } ~ 50 \% \text { for the biocontrol fungus, Fusarium } \\
\text { oxysporum CS- } 20\end{array}$ & [42] \\
\hline & Chlorothalonil & Bees & $\begin{array}{l}\text { Altered structure of gut bacterial communities alongside predicted functional } \\
\text { changes to carbohydrate metabolism after } 6 \text {-week exposure }\end{array}$ & [43] \\
\hline & $\begin{array}{l}\text { Pristine (boscalid and } \\
\text { pyraclostrobin mixture) }\end{array}$ & Bees & $\begin{array}{l}\text { Dose-dependent compositional changes in the relative abundance of } \\
\text { Gilliamella spp. and Lactobacillus Firm-4/Firm-5 members after 21-day } \\
\text { exposure }\end{array}$ & [44] \\
\hline
\end{tabular}

DDT: Dichlorodiphenyltrichloroethane.

inhibitory effects on microbial growth and overall metabolic activities at the community level in soil ${ }^{[28,46]}$. Data from in vitro culture-based studies on hundreds of soil bacterial isolates confirm these effects, showing inhibition of $\sim 74 \%-100 \%$ of the tested Gram-positive strains when exposed to field-realistic concentrations of $\gamma$-hexachlorocyclohexane, bandane, chlordane, heptachlor, and other OCLs ${ }^{[27,47]}$. Dichlorodiphenyltrichloroethane (DDT) is another well-known OCL with potent antibacterial properties, and under field conditions causes a $~ 60 \%$ decrease in active soil bacterial biomass and a $\sim 93 \%$ increase in fungal biomass ${ }^{[28]}$ - the latter of which likely represents an indirect response to the former via reduced competition, rather than a stimulatory response to DDT since OCLs are notoriously recalcitrant to breakdown. 


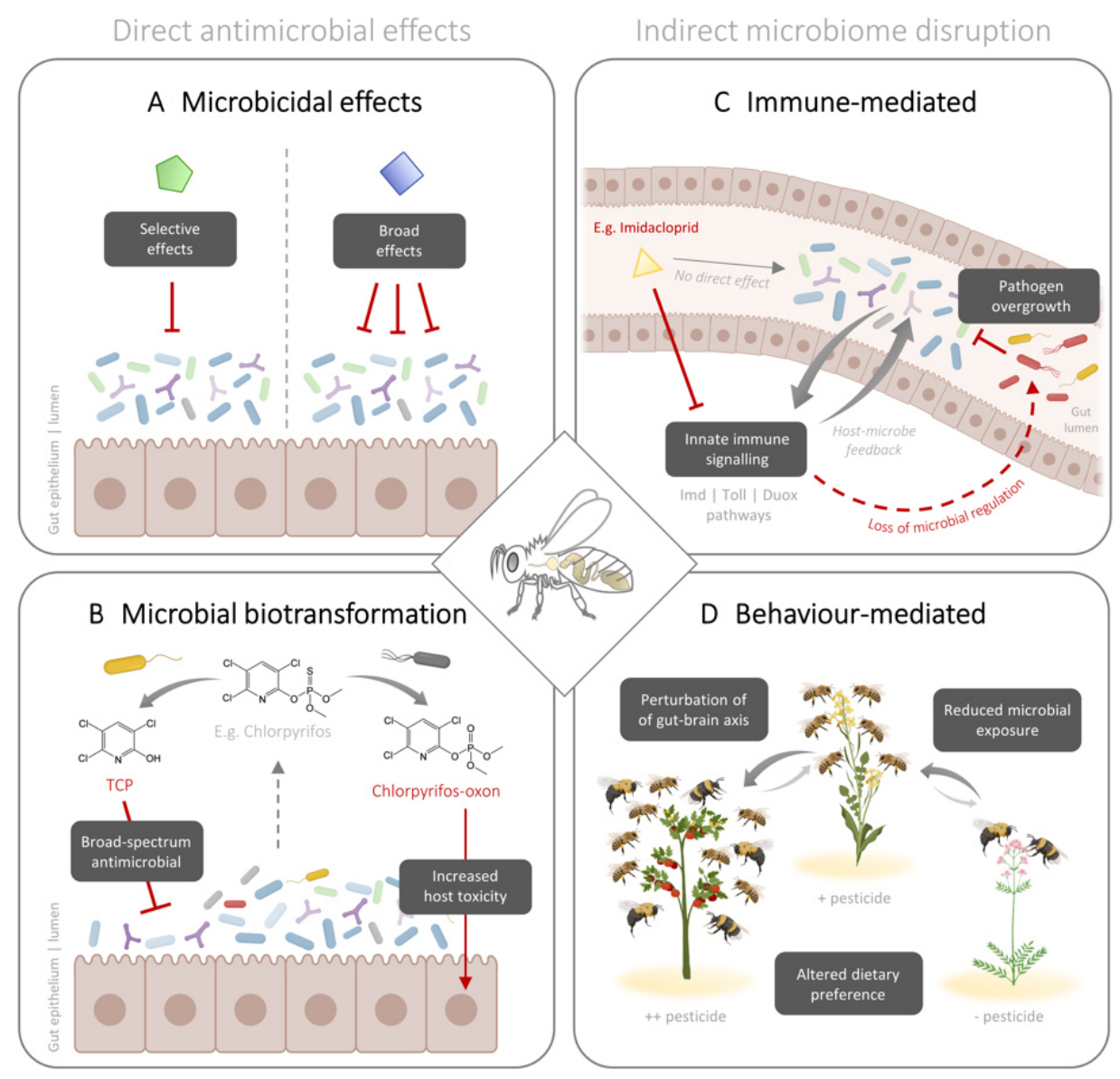

Figure 2. Direct and indirect mechanisms through which "non-antimicrobial" pesticides deteriorate bee-associated microbial communities. The panels on the left (A, B) highlight how both the parent compound and breakdown metabolites of pesticides can cause direct harm to microbial cells. The panels on the right (C, D) highlight how pesticides can alter microbial homeostasis through modulating host immune gene expression and behaviour in honey bees.

Importantly, the mechanism by which OCLs exert their differential antimicrobial effects has long been assumed to be through non-specific physicochemical disruption of (primarily Gram-positive) membraneassociated processes (e.g., ionic transport, electron transport, cell wall biosynthesis), ultimately leading to cell lysis and loss of viability ${ }^{[4]}$. That is, the antimicrobial effects of OCLs were thought to be random and independent from their designed functions of inhibiting insect GABAergic signalling. Recent evidence, however, suggests that GABA signalling (beyond its recognized role of neurotransmission in animals) plays a major role in cross-kingdom chemical communication and quorum sensing events that actively regulate bacterial-archaeal-fungal community structure ${ }^{[49]}$. GABA has also been found to represent an essential bacterial nutrient in certain Gram-positive bacteria, such as the recently identified human gut isolate, Candidatus "Evtepia gabavorous" [50]. Taken together, this suggests that the antimicrobial effects of OCLs are not random and may in fact be related to their inhibitory effects on GABAergic signalling. While OCLs are now banned in most countries due to their environmental persistence (facilitated at least in part by inhibition of their own bioremediation ${ }^{[48]}$ ) and association with a broad range of other wildlife health concerns ${ }^{[51]}$, they provide an exemplary account of host-microbiome interconnectedness and how intentional insecticidal properties can directly translate into unintentional microbicidal properties [Figure 1]. 
Other, perhaps more obvious examples of pesticides with antimicrobial properties are those of fungicides (or simply antifungals when considered beyond their agricultural usage). Pollinating insects are exposed to especially high levels of fungicides since they are considered "bee-safe" (in terms of acute toxicity) and are typically applied during periods of peak pollen bloom to prevent the growth of crop disease-causing fungal pathogen $s^{[52]}$. Perhaps unsurprisingly, a two-year study in managed honey bees showed that in-hive fungicide contamination was strongly associated with reduced overall fungal concentration and genus-level fungal diversity in beebread ${ }^{[53]}$ - the main dietary staple of honey bees which consists mostly of collected pollen. This is important since mounting evidence suggests that fungicides are negatively associated with pollinator health despite lacking signs of acute toxicity ${ }^{[33-55]}$, and that reductions in beneficial fungi are associated with poorer pollinator nutrition and increased susceptibility to fungal disease (e.g., Chalkbrood caused by Ascosphaera apis) ${ }^{[56]}$. Moreover, certain fungal steroids (produced by Zygosaccharomyces spp.) have recently been identified as essential to the development of stingless bees, which otherwise fail to pupate in their absence ${ }^{[57]}$. These findings potentially explain why group $\mathrm{G}$ fungicides (targeting sterol-biosynthesis) were disproportionately associated with colony loss in a large-scale study on migratory honey bee operations in the United States ${ }^{[58]}$.

Less intuitively, a broad range of fungicides (e.g., azoxystrobin, chlorothalonil, propamocarb, and propiconazole) can also negatively influence bacterial communities found in association with bees ${ }^{[43,59,60]}$. It is, however, difficult to ascertain the mode of action since the findings are correlative in nature. Based on the fact that supplementation of beneficial fungi in bees (e.g., Aureobasidium melanogenum) can increase bacterial community abundance ${ }^{[6]}$, it could be reasoned that a reduction in beneficial fungi (e.g., in response to fungicide exposure) may also have a negative effect on bacterial loads. Evidence from plants and rodent models supports the notion that fungi can play a major role in mediating community assembly within the rhizosphere microbiome ${ }^{[62]}$ and animal gut microbiome ${ }^{[63]}$, respectively. Fungicide-induced changes in bacterial communities could thus simply be the result of destabilized fungal-bacterial metabolic networks. Nonetheless, azole-based fungicides possess well established antibacterial properties ${ }^{[64]}$ and Khan et al. ${ }^{[41]}$ recently demonstrated in vitro that the two disjunct fungicides, hexaconazole and carbendazim (targeting sterol biosynthesis and microtubule assembly processes, respectively), could both exert direct bactericidal effects against plant growth-promoting Pseudomonas spp. in a dose-dependent manner - the mechanisms, however, have not yet been elucidated. Altogether, the current literature suggests that fungicides can directly disrupt host-associated microbiomes in multifaceted ways and that these offtarget effects (which functionally diminish plant and animal health) are vastly understudied.

Lastly, glyphosate (commonly known as "RoundUp") is the most popular herbicide used worldwide for weed control but has been associated with extensive disruption to plant and animal microbiomes ${ }^{[65]}$. These effects are explained by the fact that glyphosate targets the 5-enolpyruvyl-shikimate-3-phosphate synthase (EPSPS) enzyme used in the shikimate pathway (a central metabolic route affecting many adaptive processes $^{[15]}$ ) of plants, bacteria, archaea, fungi, and some protozoa. Animals notably do not possess this pathway and thus glyphosate should theoretically demonstrate low toxicity towards them. In honey bees, however, Motta et al. ${ }^{[66]}$ demonstrated that glyphosate exposure results in dose-dependent, microbiomemediated toxicity and reduced survival during infection with the Gram-negative opportunistic entomopathogen, Serratia marcescens. Data from in vitro studies support that glyphosate [rather than its breakdown metabolite aminomethylphosphonic acid (AMPA)] is the responsible factor involved and can exert differential antimicrobial properties on the basis of EPSPS class I (sensitive) and II (resistant) binding affinities ${ }^{\left[{ }^{67]}\right.}$. The honey bee symbiont, Snodgrassella alvi, encoding a class I-type EPSPS has been reported to be consistently lower in abundance during exposure to glyphosate ${ }^{[39]}$. Together with evidence of $S$. alvimediated immunoregulatory roles ${ }^{[68]}$, this could potentially strengthen the otherwise somewhat obscure 
linkages between field-realistic glyphosate exposure and apparent susceptibility of honey bees to viral (Deformed wing virus) and fungal (Nosema ceranae) pathogen $s^{[6]]}$.

Glyphosate can similarly increase the prevalence of root rot-inducing Fusarium spp. in the plant rhizosphere microbiome by inhibiting plant symbionts which otherwise antagonize the growth of the pathogen $^{[40]}$. Moreover, the directly antifungal effects of glyphosate can impair mycorrhizal colonization and alter plant-soil nutrient cycling dynamics ${ }^{[70]}$ - an effect that can lead to long-term stunting of plant growth and a gradual reduction of crop yields ${ }^{[7]}$. While some studies contest the microbiome-mediated stunting effects of glyphosate ${ }^{[72,73]}$, a meta-analysis on the topic suggests that the phenomenon is dependent on soil $\mathrm{pH}$ differences ${ }^{[74]}$, which may govern the microbial degradation rates of glyphosate to its inactivate metabolite, AMPA. Collectively, the current literature indicates that glyphosate (and many other types of herbicides ${ }^{[75]}$ ) can directly exert unintentional antimicrobial effects on plant- and animal-associated microbial communities, and that these changes can consequently impair host developmental processes and disease resistance.

\section{Indirect antimicrobial effects via host-mediated immune dysregulation}

Neonicotinoid-based insecticides, which induce neurotoxic effects via selective inhibition of insect nicotinic acetylcholine receptors, are widely popular as a result of their very low toxicity towards humans, but have faced much scrutiny with regard to their controversial association with declining pollinator populations ${ }^{[76]}$. One such topic of controversy is the administration of neonicotinoids, which are designed as "systemic pesticides" intended for uptake and distribution within plant tissue - the goal being to maximize target pest exposure while minimizing environmental contamination. However, neonicotinoids also accumulate in the plant root exudate and pollen (in the case of angiosperm plants) ${ }^{[77]}$, meaning that the rhizosphere microbiome and the gut microbiome of pollinating insects (via oral consumption of pollen) are the primary recipients of chronic off-target exposure. Nonetheless, studies on the antimicrobial effects of neonicotinoids have been inconsistent across the literature.

In considering the effects of imidacloprid (a common neonicotinoid) on the honey bee microbiome, Raymann et al. ${ }^{[3]}$ elegantly demonstrated that there were no obvious impacts on genus-level bacterial diversity metrics (measured via $16 \mathrm{~S}$ rRNA gene sequencing) after five days of in-hive exposure. In the same study, in vitro exposure of 16 honey bee gut-derived bacterial isolates showed essentially no sensitivity (nor degradation ability) of the strains towards imidacloprid in mono- or mixed-culture experiments. Despite these seemingly conclusive findings, a follow-up study testing longer exposure durations (as would be expected from chronic hive contamination under realistic situations ${ }^{[78]}$ ) found that imidacloprid (and thiacloprid) exerted a time-dependent decrease in both bacterial and fungal community alpha diversity, with the most significant changes occurring after five weeks ${ }^{[34]}$. Empirical evidence also suggests that clothianidin $^{[30]}$, nitenpyram ${ }^{[36]}$, thiamethoxam ${ }^{[79]}$, and other types of neonicotinoids ${ }^{[80]}$ can exert bee microbiome-disrupting side effects during longer periods of chronic exposure, although the responsible mechanism remains unclear.

One explanation could be that the immunosuppressive effects of neonicotinoids (thought to be at the root of globally declining populations of bees, fish, amphibians, bats, and birds ${ }^{[8]}$ ) act to reduce host-mediated selective pressures on microbial communities. This notion is supported by the fact that antimicrobial peptides (AMPs) and other effector molecules produced by the insect innate immune system (e.g., Imd, Toll, and DUOX pathways $\left.{ }^{[82,83]}\right)$ possess crucial microbiome-shaping properties via their differential activities against phylogenetically distinct microbial lineages. For example, the honey bee AMP, apidaecin, demonstrates magnitudes lower activity against Gram-negative symbionts (e.g., G. apicola and Snodgrassella 
alvi found abundantly in healthy bees) compared with Gram-negative opportunistic pathogens (e.g., Escherichia coli $^{[84]}$. A noteworthy point to highlight is that host-adapted symbionts possess unique functions, that in return, help shape innate immune signaling ${ }^{[68]}$. That is, the persistence of host-adapted microbial communities is a bidirectional process, and thus this may functionally explain how immune dysregulation by neonicotinoids could (indirectly) result in a loss of microbial diversity over time under realistic scenarios of chronic exposure. It is also foreseeable how these effects could exacerbate the loss of microbial diversity during concurrent exposure to chemicals that do possess antimicrobial capacities, such is the case for antibiotics ${ }^{[85]}$ and fungicides ${ }^{[86]}$ - the latter of which is consistent with results showing a near doubling of the apparent honey bee mortality risk over a four-month period during neonicotinoid coexposure ${ }^{[78]}$. Collectively, the current literature suggests that the microbiome-disrupting effects of pesticides are not always as clear as direct inhibition, and in the case of neonicotinoids in bees, appear to be mediated indirectly via host immune dysregulation [Figure $2 \mathrm{C}$ ], and at concentrations not otherwise directly toxic to bee physiology.

\section{Biotransformation-dependent antimicrobial effects}

The potential direct antimicrobial effects of neonicotinoids cannot be ruled out based on bee microbiome studies alone. Nicotine represents a plant-produced signaling molecule known to interact with soil bacteria and fungi ${ }^{[87]}$, and thus neonicotinoids (i.e., structurally derived from nicotine) could foreseeably have a higher probability of interacting with plant-associated microbial communities. In the case of rice (Oryza sativa) crops, imidacloprid has been found to decrease diversity metrics in the rhizosphere microbiome, with impact severity shown to be both dose- and duration-dependent ${ }^{[33]}$. Thus, this could potentially imply an indirect plant-defense mediated response (i.e., similar to bees) given that imidacloprid (and thiamethoxam) can significantly reduce plant immune-related gene expression ${ }^{[8]}$. Nonetheless, laboratory studies on sandy soils (which deconvolute the potentially confounding variables of plant host-mediated responses on the rhizosphere microbiome) instead suggest that neonicotinoids can have a direct inhibitory effect on nitrifying organism $\mathrm{s}^{[8]]}$, specifically reducing that of ammonia-oxidizing archaea and bacteria in a species-specific manner ${ }^{[32]}$. These findings are supported by other soil experiments also showing a dosedependent decrease in important soil enzymatic activities (e.g., $\beta$-glycosidase, fluorescein diacetate hydrolase, acid phosphatase and urease) alongside a $\sim 37 \%$ reduction in culturable fungi after 30 days of imidacloprid exposure ${ }^{[3]]}$. Given that neonicotinoids can persist in soil for $>1000$ days in some cases ${ }^{[00]}$, these effects could foreseeably disrupt long-term microbial homeostasis.

Overall, very little mechanistic work has been done to understand the antimicrobial effects of neonicotinoids, with the bulk of literature focusing on in vitro studies of soil isolates with neonicotinoiddegrading properties. Interestingly, many of these isolates are nitrifying or N2-fixing bacteria such as thiacloprid-degrading Microvirga flocculans ${ }^{[35]}$, thiamethoxam-degrading Ensifer adhaerens ${ }^{[91]}$, imidaclopriddegrading Pseudomonas putida ${ }^{[2]}$. Moreover, in each of these cases, as well in fungal degradation of imidacloprid by Aspergillus terreus ${ }^{[93]}$, the breakdown is directly coupled with growth impairment of the metabolizing strain - suggesting that neonicotinoid metabolites (e.g., nitroso-, guanidine-, and urea ${ }^{[2]}$ ) are the responsible antimicrobial factors involved, rather than the parent compounds. Other examples exist with at least 40 neonicotinoid-degrading isolates identified so far, mostly from soil or water environments (see review ${ }^{[94]}$ ). Notably, the preferential impact of neonicotinoids on plant growth-promoting $\mathrm{N}_{2}$-fixing bacteria appears to have long-term adverse outcomes in chickpea and soybean crop yields ${ }^{[95,96]}$, although data from corn crops show inconsistencies ${ }^{[97]}$. While these differences could potentially be attributable to variation in soil parameters (e.g., organic matter, $\mathrm{pH}$, temperature, etc.) known to influence the behaviour of neonicotinoids ${ }^{[98,99]}$, there is, overall, a lack of literature on the topic and further studies are needed before any solid conclusions can be drawn. 
Unlike animals, which rely on their diet for nitrogen via protein consumption, plants absorb nitrogen through their roots, often with the help of their associated microbiomes. This might explain why honey beeassociated microbial communities cannot degrade neonicotinoids and appear to be largely unaffected by their presence in culture ${ }^{[31]}$. It is nonetheless interesting to consider how insect-mediated detoxification of neonicotinoids (which also produces neonicotinoid metabolites, prior to excretion via the fecal-route ${ }^{[100]}$ ) could have insidious effects on the gut microbiome through activating the antimicrobial effects of these compounds. This has yet to be tested and would be a worthy direction for future studies. To note as well, microbial biotransformation-dependent toxicity of pesticides is not a unique process to neonicotinoids (see Table 1). Symbiont-mediated degradation of chlorpyrifos (a common organophosphate insecticide) in Drosophila melanogaster, for example, exerts pleiotropic effects by producing two metabolites chlorpyrifos-oxon (with 10- to 100-fold higher insecticidal activity towards the host) and 3,5,6-trichloro-2pyridinol (with potent antimicrobial effects on the gut microbiome) ${ }^{[101]}$ [Figure 2B]. Further, in pest insects such as the diamondback moth, alydid stinkbug, and crucifer root maggot, the degradation of various pesticides by microbial symbionts can infer insecticide resistance ${ }^{[102-105]}$. Together, these findings provide a basis to speculate on how "biopesticides" (i.e., microorganisms used for pest control) could be favorably utilized in tandem with pesticides to increase their insecticidal properties by in vivo biotransformation to more toxic metabolites - an approach that has been proposed in several emerging microbiome management strategies for agroecosystems ${ }^{[106]}$.

Overall, the discussed material cumulatively highlights three major points: (1) plant- and animal-associated microbiomes intrinsically differ in their sensitivity towards certain pesticides; (2) microbiome-mediated biotransformation of pesticides can produce antimicrobial metabolites from otherwise non-antimicrobial parent compounds; and (3) strategic modulation of host-associated microbiomes in agricultural systems has potential to offset adverse pesticide interactions.

\section{Behaviour-mediated antimicrobial effects}

The antimicrobial effect of pesticides on pollinating insects can be amplified to a systems level through indirect effects on foraging and other social behaviours [Figure 2D]. Using the honey bee (A. mellifera) as an example, individual worker bees, which number in the tens of thousands per colony, forage separately for pollen and nectar. However, their industry is not selfish - instead, they return their foraged goods to the hive where it is concentrated into honey and pollen stores and ultimately fed to developing larvae ${ }^{[107]}$. The social foraging and otherwise colony-oriented behaviour of worker bees thus naturally concentrates any trace environmental contaminants from afar into higher, localized concentrations that can then accumulate and in some cases reach toxic levels ${ }^{[108]}$. Honey bees and other eusocial insects with this type of centralized foraging are thus vulnerable to bioaccumulation of neonicotinoids and other applied contaminants. The direct effects of pesticides on honey bee physiology have been intensely investigated ${ }^{[109]}$ but less is known about the indirect effects that likely arise from pesticide-mediated microbiome disruption and the downstream effects that this dysbiosis can have on individual and social behaviour.

Unique among insects, honey bees (as well as bumble bees) possess a "core" gut microbiome structure ${ }^{[110]}$ consisting of 8-10 species clusters within the genera Gilliamella, Snodgrassella, Bombella, Lactobacillus, Apilactobacillus, and Bombilactobacillus ${ }^{[11]}$. This community is remarkably consistent across environments ${ }^{[112]}$, suggesting a strongly co-adapted symbiosis is crucial to the maintenance of bee health and immunity ${ }^{[113]}$. For honey bees and other social insects in which individual behaviour has become integrated into a whole, the composition of symbiotic gut microbes can influence not only the behaviour of individual insects but also the collective behaviour of entire societies in which they live $e^{[114]}$. The brain-gut-microbiome axis is one mechanism by which gut microbiomes can influence the individual performance and social behaviour of workers within the hive ${ }^{[115]}$. Perturbation of this axis via pesticide-mediated depletion of core 
microbiome members should therefore affect bee behaviour in predictable and potentially manageable ways. For example, antimicrobial effects on bee gut microbiomes may alter foraging behaviour via individual performance or dietary preference ${ }^{[116]}$, which when amplified across all individuals and colonies, can impact pollination services.

Interestingly, the learning performances of honey bees are differentially affected by imidacloprid according to the season ${ }^{[117]}$. Underpinning this phenomenon could be the substantial fluctuation in gut microbiome structure known to occur between winter and summer seasons ${ }^{[118]}$. There is ample opportunity for feedback between host and microbiome if, for example, initial changes to microbial communities then bias foraging preference to influence the plant-associated microbes the bees are exposed to. Subtle behavioural changes (i.e., otherwise not impacting host survival by itself) could thus hinder natural plant-pollinator microbial exchange processes and influence the long-term maintenance of co-adapted symbionts. Some remediation may be possible through the application of beneficial bacteria that off-set the dysbiosis inadvertently caused by the well-intended application of commercial antibiotics ${ }^{[85]}$ or pesticides ${ }^{[119]}$ to hives.

Given that bee social behaviour is highly coordinated, where the worker caste can specialize into behavioural subcastes that, besides foragers, include nurses, guards, hygienists, undertakers and scouts ${ }^{[120]}$, we expect any significant variation in the gut microbiome to affect the bee's most fundamental behaviours, including recruitment, hygienic, defensive and appetitive behaviours - all of which are essential to colony's eusocial structure ${ }^{[121]}$. For humans, communication along the brain-gut axis is mediated through immune mechanisms, elements of the nervous system and microbial metabolites that relay nutrition and health status from the gut to the brain ${ }^{[122]}$. For insects and bees in particular, the mechanics of this axis are less well defined, however, because social insects have evolved a particularly strong dependence upon gut symbionts ${ }^{[6]}$, there is a strong rationale for investigation of this topic in future studies.

\section{LINKAGES BETWEEN PESTICIDE EXPOSURE AND ANTIMICROBIAL RESISTANCE}

Pesticides, like antibiotics, represent chemical stressors that can exert selective pressures on microbial communities. Mounting evidence suggests that the evolution of tolerance, resistance, and persistence ${ }^{[123]}$ towards pesticides may consequently impact microbial response to antibiotics through both generalizable and specific mechanisms ${ }^{[124]}$. This represents a major human health concern in relation to the rise of multidrug-resistant pathogens (or "superbugs") and hospital-acquired infections that are increasingly difficult to treat.

One mechanism of overlapping resistance is through efflux pumps (e.g., SMR and MATE families in particular ${ }^{[125]}$, which are membrane-bound transporters that can export multiple toxic substrates out of the cell. For example, Kurenbach et al. ${ }^{[126]}$ found that pre-exposure of E. coli to two herbicides (glyphosate and dicamba) could significantly increase subsequent tolerance against two broad-spectrum antibiotics (chloramphenicol and kanamycin) via overexpression of the AcrAB efflux pump - an effect that failed to occur in the presence of efflux pump inhibitor Phe-Arg $\beta$-naphtylamide. Others have also reported that biocide usage selects for overexpression of efflux pumps ${ }^{[127]}$. Alternatively, a study on realistic co-exposure of 23 pesticides in $E$. coli demonstrated that streptomycin-resistance emerged rapidly via selected for mutations in $a c r R$ (encoding a transcriptional repressor that regulates $a c r A B$ expression) as well as biofilm, heat shock, oxidative stress defense, and carbon starvation genes ${ }^{[128]}$.

In the case that pesticides cannot be pumped out of the cell, intrinsic or acquired enzymatic functions can facilitate overlapping resistance to antibiotics. For example, the plasmid-encoded organophosphorus hydrolase (OPH) of insecticide-degrading Bacillus isolates (e.g., B. cereus, B. firmus, and B. thuringiensis 
strains from contaminated agricultural sites) can confer multidrug resistance by inactivating chloramphenical, monochrotophos, ampicillin, cefotaxime, streptomycin and tetracycline antibiotics ${ }^{[129]}$. The noteworthy point is that similar or identical OPHs have been found in Pseudomonas, Flavobacterium, Sphingobium, and Agrobacterium spp. ${ }^{[130-132]}$, with molecular evidence suggesting the response genes have probably evolved within the past 70 years $^{[133]}$. This coincides directly with the introduction of organophosphate insecticides and the global rise of antibiotic resistance, and thus it is interesting to speculate how these processes have co-impacted the evolutionary trajectory of microbial life. Similar comparisons can be made for several oxidoreductases, transferases, and lyases in terms of conferring overlapping pesticide and antibiotic resistance properties ${ }^{[124]}$.

\section{FUTURE DIRECTIONS}

Several important areas have been highlighted in this review that deserve future scrutiny. These are summarized below:

(1) Currently, regulatory oversight of agrochemical usage is inadequate and fails to address potential effects on ecosystem microbiomes which are in turn critical to environmental health. A reassessment of the legislative framework that governs the use of agrochemicals is urgently warranted.

(2) Agrochemical toxicity is generally defined as a construct of their direct and acute harmfulness towards plant and animal species, whereas their detrimental effects on plant- and animal-associated microbiomes are likely to have more subtle, accumulative consequences. Long-term studies of plant and animal health (including measurements of microbiome diversity, composition and activity) following exposure to agricultural compounds are required to allow balanced calculation of risk $v s$. benefit of agrochemical use.

(3) Microbial biotransformation of agrochemicals is understudied and requires urgent evaluation if we are to fully understand the impact of a given compound on the environment. Relatedly, bioremediation efforts need to account for potential adverse effects of breakdown metabolites on not only plant and animal physiology, but also their host-associated microbial communities.

(4) Antimicrobial resistance is a current global threat to health, and it is imperative that the role of agrochemical use in the development of antimicrobial resistance is fully studied and appreciated.

(5) The gut-microbiome-brain axis is an emerging field of interest with relevance to pesticideneuroimmune interactions and merits particular attention in eusocial bee species, such as honey bees, which exhibit strong interdependencies on their gut microbiomes.

In addressing these issues as they relate to microbiome-mediated pesticide toxicity, proof of causality is an important factor to consider. Multi-omics technologies have massively improved our ability to identify taxonomic- and functional-based correlations of host-associated microbial communities in response to agrochemical exposures. However, demonstrating an association between pesticide exposure and microbiome change is not enough to authenticate an antimicrobial effect. As discussed in this review, it remains challenging (due to confounding host variables) to delineate between direct antimicrobial properties and indirect microbiome disrupting activities based on in vivo observation alone [Figure 2]. Indeed, culture-based interrogation of host-derived isolates in vitro can be extremely informative, although not all microbes are culturable and pesticide co-culture experiments with single strains are not adequately representative of the highly complex polymicrobial interactions that may occur under natural conditions (see Ref. ${ }^{[134]}$ for review on methodological challenges of pesticide risk assessment). 
Collectively, this indicates a substantial need for model development of host-free rhizosphere and insect gut microbiome systems. Bioreactor models for the human gut microbiome already exist (e.g., benchtop "Robogut" ${ }^{\text {"[135] }}$ and SHIME systems ${ }^{[136]}$ ) and are actively being used to decipher microbe-drug interactions relevant to human disease treatments ${ }^{[137]}$. Notably, these systems may be easily adapted for agricultural purposes as well, specifically allowing for high-throughput evaluation of microbe-pesticide interactions pertaining to honey bee health, commercial crop yield, and environmental health as a whole. Future development and testing of such models should be an immediate priority based on the fact that current pesticide risk assessment strategies could also benefit from their use by improving the veracity of new product safety claims prior to their release.

\section{OUTLOOK AND CONCLUDING REMARKS}

We have outlined the multifaceted ways in which agricultural chemicals can disrupt microbial ecosystem function using examples from honey bees and crop plants. Perhaps one of the more alarming aspects of the current situation is the apparent weakness of regulatory policies, which are riddled with loopholes and largely ignore contemporary research findings on host microbiome-pesticide interactions.

There is a pressing need to reassess the use of agrochemical xenobiotics through the lens of microbial ecology and the concurrent or subsequent effects on host (animal and plant) physiology. This is not easy to do, since most microbial ecosystems are highly complex, and so much of the microbial world remains unstudied. However, tools to study microbiomes and their functions are now increasingly accessible, and should be exploited to study microbial ecosystem modulation by herbicides, insecticides and fungicides across all agricultural sectors as a matter of great urgency.

\section{DECLARATIONS}

\section{Authors' contributions}

Contributed to the conceptualization of ideas presented in the manuscript: Daisley BA, Chernyshova AM, Thompson GJ, Allen-Vercoe E

Drafted the manuscript and generated the figures: Daisley BA

All authors helped in revising the manuscript and agree to be accountable for the content of the work.

\section{Availability of data and materials}

Not applicable.

\section{Financial support and sponsorship}

This work was supported a Natural Sciences and Engineering Research Council of Canada (NSERC) Discovery Grant (RGPIN-2020-05647) and an NSERC Postdoctoral Fellowship Award (PDF-558010-2021).

\section{Conflicts of interest}

All authors declared that there are no conflicts of interest.

\section{Ethical approval and consent to participate}

Not applicable.

\section{Consent for publication}

Not applicable. 


\section{Copyright}

(C) The Author(s) 2022.

\section{REFERENCES}

1. Banerjee S, Schlaeppi K, van der Heijden MGA. Keystone taxa as drivers of microbiome structure and functioning. Nat Rev Microbiol 2018;16:567-76. DOI PubMed

2. Wabnitz K, Gabrysch S, Guinto R, et al. A pledge for planetary health to unite health professionals in the Anthropocene. Lancet 2020;396:1471-3. DOI PubMed PMC

3. Trinh P, Zaneveld JR, Safranek S, Rabinowitz PM. One health relationships between human, animal, and environmental microbiomes: a mini-review. Front Public Health 2018;6:235. DOI PubMed PMC

4. Guerrero R, Margulis L, Berlanga M. Symbiogenesis: the holobiont as a unit of evolution. Int Microbiol 2013;16:133-43. DOI PubMed

5. Moran NA, Ochman H, Hammer TJ. Evolutionary and ecological consequences of gut microbial communities. Annu Rev Ecol Evol Syst 2019;50:451-75. DOI PubMed PMC

6. Barribeau SM, Sadd BM, du Plessis L, et al. A depauperate immune repertoire precedes evolution of sociality in bees. Genome Biol 2015;16:83. DOI PubMed PMC

7. Busby PE, Soman C, Wagner MR, et al. Research priorities for harnessing plant microbiomes in sustainable agriculture. PLoS Biol 2017;15:e2001793. DOI PubMed PMC

8. Ramírez-Puebla ST, Servín-Garcidueñas LE, Jiménez-Marín B, et al. Gut and root microbiota commonalities. Appl Environ Microbiol 2013;79:2-9. DOI PubMed PMC

9. Foster KR, Schluter J, Coyte KZ, Rakoff-Nahoum S. The evolution of the host microbiome as an ecosystem on a leash. Nature 2017;548:43-51. DOI PubMed PMC

10. CERIS. National Pesticide Information Retrieval System. Available from: http://npirspublic.ceris.purdue.edu/ppis [Last accessed on 25 Jan 2022].

11. Prescott SL, Wegienka G, Logan AC, Katz DL. Dysbiotic drift and biopsychosocial medicine: how the microbiome links personal, public and planetary health. Biopsychosoc Med 2018;12:7. DOI PubMed PMC

12. FAO. Pesticide use. Global, regional and country trends 1990-2018. Available from: https://fao.org/documents/card/en/c/cb3411en/ [Last accessed on 25 Jan 2022].

13. Blaser MJ. The theory of disappearing microbiota and the epidemics of chronic diseases. Nat Rev Immunol 2017;17:461-3. DOI PubMed

14. Musso G, Gambino R, Cassader M. Obesity, diabetes, and gut microbiota: the hygiene hypothesis expanded? Diabetes Care 2010;33:2277-84. DOI PubMed PMC

15. Daisley BA, Koenig D, Engelbrecht K, et al. Emerging connections between gut microbiome bioenergetics and chronic metabolic diseases. Cell Rep 2021;37:110087. DOI PubMed

16. Franzosa EA, Sirota-Madi A, Avila-Pacheco J, et al. Gut microbiome structure and metabolic activity in inflammatory bowel disease. Nat Microbiol 2019;4:293-305. DOI PubMed PMC

17. Qin J, Li Y, Cai Z, et al. A metagenome-wide association study of gut microbiota in type 2 diabetes. Nature 2012;490:55-60. DOI PubMed

18. Liu R, Hong J, Xu X, et al. Gut microbiome and serum metabolome alterations in obesity and after weight-loss intervention. Nat Med 2017;23:859-68. DOI PubMed

19. Jie Z, Xia H, Zhong SL, et al. The gut microbiome in atherosclerotic cardiovascular disease. Nat Commun 2017;8:845. DOI PubMed PMC

20. Helmink BA, Khan MAW, Hermann A, Gopalakrishnan V, Wargo JA. The microbiome, cancer, and cancer therapy. Nat Med 2019;25:377-88. DOI PubMed

21. Johnson RM, Ellis MD, Mullin CA, Frazier M. Pesticides and honey bee toxicity - USA. Apidologie 2010;41:312-31. DOI

22. Rani L, Thapa K, Kanojia N, et al. An extensive review on the consequences of chemical pesticides on human health and environment. J Clean Prod 2021;283:124657. DOI

23. Köhler HR, Triebskorn R. Wildlife ecotoxicology of pesticides: can we track effects to the population level and beyond? Science 2013;341:759-65. DOI PubMed

24. Sharma A, Kumar V, Shahzad B, et al. Worldwide pesticide usage and its impacts on ecosystem. SN Appl Sci 2019;1:1446. DOI

25. EPA. Pesticide Registration Process. Environ Prot Agency 2021. Available from: https://epa.gov/pesticide-science-and-assessingpesticide-risks/overview-risk-assessment-pesticide-program [Last accessed on 25 Jan 2022].

26. eCFR. Protection of Environment. Code Fed Regul 2013. Available from: https://.ecfr.gov/current/title-40 [Last accessed on 29 November 2021].

27. Trudgill PW, Widdus R, Rees JS. Effects of organochlorine insecticides on bacterial growth, respiration and viability. $J$ Gen Microbiol 1971;69:1-13. DOI PubMed

28. Bollen WB, Morrison HE, Crowell HH. Effect of field and laboratory treatments with BHC and DDT on nitrogen transformations and soil respiration1. J Econ Entomol 1954;47:307-12. DOI

29. Nogrado K, Lee S, Chon K, Lee J. Effect of transient exposure to carbaryl wettable powder on the gut microbial community of honey bees. Appl Biol Chem 2019;62:6. DOI 
30. Khoury S, Gauthier J, Bouslama S, Cheaib B, Giovenazzo P, Derome N. Dietary contamination with a neonicotinoid (Clothianidin) gradient triggers specific dysbiosis signatures of microbiota activity along the honeybee (Apis mellifera) digestive tract. Microorganisms 2021;9:2283. DOI PubMed PMC

31. Raymann K, Motta EVS, Girard C, Riddington IM, Dinser JA, Moran NA. Imidacloprid decreases honey bee survival rates but does not affect the gut microbiome. Appl Environ Microbiol 2018;84:e0545-18. DOI

32. Cycoń M, Piotrowska-Seget Z. Community structure of ammonia-oxidizing archaea and ammonia-oxidizing bacteria in soil treated with the insecticide imidacloprid. Biomed Res Int 2015;2015:582938. DOI PubMed PMC

33. Mahapatra B, Adak T, Patil NKB, et al. Imidacloprid application changes microbial dynamics and enzymes in rice soil. Ecotoxicol Environ Saf 2017;144:123-30. DOI PubMed

34. Alberoni D, Favaro R, Baffoni L, Angeli S, Di Gioia D. Neonicotinoids in the agroecosystem: In-field long-term assessment on honeybee colony strength and microbiome. Sci Total Environ 2021;762:144116. DOI PubMed

35. Zhao Y, Jiang H, Cheng X, et al. Neonicotinoid thiacloprid transformation by the N2-fixing bacterium Microvirga flocculans CGMCC 1.16731 and toxicity of the amide metabolite. Int Biodeterior Biodegrad 2019;145:104806. DOI

36. Zhu L, Qi S, Xue X, Niu X, Wu L. Nitenpyram disturbs gut microbiota and influences metabolic homeostasis and immunity in honey bee (Apis mellifera L.). Environ Pollut 2020;258:113671. DOI PubMed

37. Fox JE, Starcevic M, Kow KY, Burow ME, McLachlan JA. Nitrogen fixation. Endocrine disrupters and flavonoid signalling. Nature 2001;413:128-9. DOI PubMed

38. Santoro PH, Cavaguchi SA, Alexandre TM, Zorzetti J, Neves PMOJ. In vitro sensitivity of antagonistic Trichoderma atroviride to herbicides. Braz arch biol technol 2014;57:238-43. DOI

39. Motta EVS, Raymann K, Moran NA. Glyphosate perturbs the gut microbiota of honey bees. Proc Natl Acad Sci U S A 2018;115:10305-10. DOI PubMed PMC

40. Fernandez M, Zentner R, Basnyat P, Gehl D, Selles F, Huber D. Glyphosate associations with cereal diseases caused by Fusarium spp. in the Canadian Prairies. Eur J Agron 2009;31:133-43. DOI

41. Khan S, Shahid M, Khan MS, et al. Fungicide-tolerant plant growth-promoting rhizobacteria mitigate physiological disruption of white radish caused by fungicides used in the field cultivation. Int J Environ Res Public Health 2020;17:7251. DOI PubMed PMC

42. Fravel D, Deahl K, Stommel J. Compatibility of the biocontrol fungus Fusarium oxysporum strain CS-20 with selected fungicides. Biological Control 2005;34:165-9. DOI

43. Kakumanu ML, Reeves AM, Anderson TD, Rodrigues RR, Williams MA. Honey bee gut microbiome is altered by in-hive pesticide exposures. Front Microbiol 2016;7:1255. DOI PubMed PMC

44. Degrandi-hoffman G, Corby-harris V, Dejong EW, Chambers M, Hidalgo G. Honey bee gut microbial communities are robust to the fungicide Pristine ${ }^{\circledR}$ consumed in pollen. Apidologie 2017;48:340-52. DOI

45. Mustard JA, Jones L, Wright GA. GABA signaling affects motor function in the honey bee. J Insect Physiol 2020;120:103989. DOI PubMed

46. MacRae IC, Raghu K, Castro TF. Persistence and biodegradation of four common isomers of benzene hexachloride in submerged soils. J Agric Food Chem 1967;15:911-4. DOI

47. Gray PHH. Effects of benzene hexachloride on soil micro-organisms. Can J Bot 1954;32:1-9. DOI

48. Shahid M, Manoharadas S, Altaf M, Alrefaei AF. Organochlorine pesticides negatively influenced the cellular growth, morphostructure, cell viability, and biofilm-formation and phosphate-solubilization activities of Enterobacter cloacae strain EAM 35. ACS Omega 2021;6:5548-59. DOI PubMed PMC

49. Quillin SJ, Tran P, Prindle A. Potential roles for gamma-aminobutyric acid signaling in bacterial communities. Bioelectricity 2021;3:120-5. DOI PubMed PMC

50. Strandwitz P, Kim KH, Terekhova D, et al. GABA-modulating bacteria of the human gut microbiota. Nat Microbiol 2019;4:396-403. DOI PubMed PMC

51. Zadoks J, Waibel H. From pesticides to genetically modified plants: history, economics and politics. NJAS - Wagening J Life Sci 2000;48:125-49. DOI

52. Mullin CA, Frazier M, Frazier JL, et al. High levels of miticides and agrochemicals in North American apiaries: implications for honey bee health. PLoS One 2010;5:e9754. DOI PubMed PMC

53. Yoder JA, Jajack AJ, Rosselot AE, Smith TJ, Yerke MC, Sammataro D. Fungicide contamination reduces beneficial fungi in bee bread based on an area-wide field study in honey bee, Apis mellifera, colonies. J Toxicol Environ Health A 2013;76:587-600. DOI PubMed

54. Park MG, Blitzer EJ, Gibbs J, Losey JE, Danforth BN. Negative effects of pesticides on wild bee communities can be buffered by landscape context. Proc Biol Sci 2015;282:20150299. DOI PubMed PMC

55. Bernauer OM, Gaines-Day HR, Steffan SA. Colonies of bumble bees (Bombus impatiens) produce fewer workers, less bee biomass, and have smaller mother queens following fungicide exposure. Insects 2015;6:478-88. DOI PubMed PMC

56. Evison SE, Jensen AB. The biology and prevalence of fungal diseases in managed and wild bees. Curr Opin Insect Sci 2018;26:10513. DOI PubMed

57. Paludo CR, Menezes C, Silva-Junior EA, et al. Stingless bee larvae require fungal steroid to pupate. Sci Rep 2018;8:1122. DOI PubMed PMC

58. Traynor KS, Pettis JS, Tarpy DR, et al. In-hive Pesticide Exposome: Assessing risks to migratory honey bees from in-hive pesticide contamination in the Eastern United States. Sci Rep 2016;6:33207. DOI PubMed PMC

59. Steffan SA, Dharampal PS, Diaz-Garcia L, Currie CR, Zalapa J, Hittinger CT. Empirical, metagenomic, and computational 
techniques illuminate the mechanisms by which fungicides compromise bee health. JVis Exp 2017. DOI PubMed PMC

60. Paris L, Peghaire E, Moné A, et al. Honeybee gut microbiota dysbiosis in pesticide/parasite co-exposures is mainly induced by Nosema ceranae. J Invertebr Pathol 2020;172:107348. DOI PubMed

61. Hsu CK, Wang DY, Wu MC. A potential fungal probiotic Aureobasidium melanogenum CK-CsC for the Western honey bee, Apis mellifera. J Fungi (Basel) 2021;7:508. DOI PubMed PMC

62. Trivedi P, Leach JE, Tringe SG, Sa T, Singh BK. Plant-microbiome interactions: from community assembly to plant health. Nat Rev Microbiol 2020;18:607-21. DOI PubMed

63. van Tilburg Bernardes E, Pettersen VK, Gutierrez MW, et al. Intestinal fungi are causally implicated in microbiome assembly and immune development in mice. Nat Commun 2020;11:2577. DOI PubMed PMC

64. Jackson CJ, Lamb DC, Kelly DE, Kelly SL. Bactericidal and inhibitory effects of azole antifungal compounds on Mycobacterium smegmatis. FEMS Microbiol Lett 2000;192:159-62. DOI PubMed

65. Syromyatnikov MY, Isuwa MM, Savinkova OV, Derevshchikova MI, Popov VN. The effect of pesticides on the microbiome of animals. Agriculture 2020;10:79. DOI

66. Motta EVS, Mak M, De Jong TK, et al. Oral or topical exposure to glyphosate in herbicide formulation impacts the gut microbiota and survival rates of honey bees. Appl Environ Microbiol 2020;86:e1150-20. DOI PubMed PMC

67. Blot N, Veillat L, Rouzé R, Delatte H. Glyphosate, but not its metabolite AMPA, alters the honeybee gut microbiota. PLoS One 2019;14:e215466. DOI PubMed PMC

68. Horak RD, Leonard SP, Moran NA. Symbionts shape host innate immunity in honeybees. Proc Biol Sci 2020;287:20201184. DOI PubMed PMC

69. Castelli L, Balbuena S, Branchiccela B, et al. Impact of chronic exposure to sublethal doses of glyphosate on honey bee immunity, gut microbiota and infection by pathogens. Microorganisms 2021;9:845. DOI PubMed PMC

70. Helander M, Saloniemi I, Omacini M, Druille M, Salminen JP, Saikkonen K. Glyphosate decreases mycorrhizal colonization and affects plant-soil feedback. Sci Total Environ 2018;642:285-91. DOI PubMed

71. Van Bruggen AHC, He MM, Shin K, et al. Environmental and health effects of the herbicide glyphosate. Sci Total Environ 2018;616617:255-68. DOI PubMed

72. Schlatter DC, Yin C, Hulbert S, Burke I, Paulitz T. Impacts of repeated glyphosate use on wheat-associated bacteria are small and depend on glyphosate use history. Appl Environ Microbiol 2017;83:e01354-17. DOI PubMed PMC

73. Ramirez-Villacis DX, Finkel OM, Salas-González I, et al. Root microbiome modulates plant growth promotion induced by low doses of glyphosate. mSphere 2020;5:e00484-20. DOI PubMed PMC

74. Nguyen DB, Rose MT, Rose TJ, Morris SG, van Zwieten L. Impact of glyphosate on soil microbial biomass and respiration: a metaanalysis. Soil Biol Biochem 2016;92:50-7. DOI

75. Ramakrishnan B, Maddela NR, Venkateswarlu K, Megharaj M. Linkages between plant rhizosphere and animal gut environments: interaction effects of pesticides with their microbiomes. Environ Adv 2021;5:100091. DOI

76. Goulson D. The insect apocalypse, and why it matters. Curr Biol 2019;29:R967-71. DOI PubMed

77. Sánchez-Bayo F. Environmental science. The trouble with neonicotinoids. Science 2014;346:806-7. DOI PubMed

78. Tsvetkov N, Samson-Robert O, Sood K, et al. Chronic exposure to neonicotinoids reduces honey bee health near corn crops. Science 2017;356:1395-7. DOI PubMed

79. Macías-Macías JO, Tapia-Rivera JC, De la Mora A, et al. Nosema ceranae causes cellular immunosuppression and interacts with thiamethoxam to increase mortality in the stingless bee Melipona colimana. Sci Rep 2020;10:17021. DOI PubMed PMC

80. Jones JC, Fruciano C, Hildebrand F, et al. Gut microbiota composition is associated with environmental landscape in honey bees. Ecol Evol 2018;8:441-51. DOI PubMed PMC

81. Mason R, Tennekes H, Sánchez-Bayo F, Jepsen P. Immune suppression by neonicotinoid insecticides at the root of global wildlife declines. J Environ Immunol Toxicol 2013;1:3-12. DOI

82. Chmiel JA, Daisley BA, Burton JP, Reid G. Deleterious effects of neonicotinoid pesticides on drosophila melanogaster immune pathways. mBio 2019;10:e01395-19. DOI PubMed PMC

83. Daisley BA, Trinder M, McDowell TW, et al. Neonicotinoid-induced pathogen susceptibility is mitigated by Lactobacillus plantarum immune stimulation in a Drosophila melanogaster model. Sci Rep 2017;7:2703. DOI PubMed PMC

84. Kwong WK, Mancenido AL, Moran NA. Immune system stimulation by the native gut microbiota of honey bees. $R$ Soc Open $S c i$ 2017;4:170003. DOI PubMed PMC

85. Daisley BA, Pitek AP, Chmiel JA, et al. Lactobacillus spp. attenuate antibiotic-induced immune and microbiota dysregulation in honey bees. Commun Biol 2020;3:534. DOI PubMed PMC

86. Woodcock BA, Bullock JM, Shore RF, et al. Country-specific effects of neonicotinoid pesticides on honey bees and wild bees. Science 2017;356:1393-5. DOI PubMed

87. Lisuma JB, Mbega ER, Ndakidemi PA. Influence of nicotine released in soils to the growth of subsequent maize crop, soil bacteria and fungi. Int J Agric Biol 2019;22:1-12. DOI

88. Wulff JA, Kiani M, Regan K, Eubanks MD, Szczepaniec A. Neonicotinoid insecticides alter the transcriptome of soybean and decrease plant resistance. Int J Mol Sci 2019;20:783. DOI PubMed PMC

89. Cycoń M, Piotrowska-Seget Z. Biochemical and microbial soil functioning after application of the insecticide imidacloprid. $J$ Environ Sci (China) 2015;27:147-58. DOI PubMed

90. Bonmatin JM, Giorio C, Girolami V, et al. Environmental fate and exposure; neonicotinoids and fipronil. Environ Sci Pollut Res Int 2015;22:35-67. DOI PubMed PMC 
91. Zhou GC, Wang Y, Zhai S, et al. Biodegradation of the neonicotinoid insecticide thiamethoxam by the nitrogen-fixing and plantgrowth-promoting rhizobacterium Ensifer adhaerens strain TMX-23. Appl Microbiol Biotechnol 2013;97:4065-74. DOI PubMed

92. Lu TQ, Mao SY, Sun SL, Yang WL, Ge F, Dai YJ. Regulation of hydroxylation and nitroreduction pathways during metabolism of the neonicotinoid insecticide imidacloprid by pseudomonas putida. J Agric Food Chem 2016;64:4866-75. DOI PubMed

93. Mohammed YMM, Badawy MEI. Biodegradation of imidacloprid in liquid media by an isolated wastewater fungus Aspergillus terreus YESM3. J Environ Sci Health B 2017;52:752-61. DOI PubMed

94. Pang S, Lin Z, Zhang W, Mishra S, Bhatt P, Chen S. Insights into the microbial degradation and biochemical mechanisms of neonicotinoids. Front Microbiol 2020;11:868. DOI PubMed PMC

95. Shahid M, Khan MS, Ahmed B, Syed A, Bahkali AH. Physiological disruption, structural deformation and low grain yield induced by neonicotinoid insecticides in chickpea: A long term phytotoxicity investigation. Chemosphere 2021;262:128388. DOI PubMed

96. Douglas MR, Rohr JR, Tooker JF, Kaplan I. EDITOR'S CHOICE: Neonicotinoid insecticide travels through a soil food chain, disrupting biological control of non-target pests and decreasing soya bean yield. J Appl Ecol 2015;52:250-60. DOI

97. Myresiotis CK, Vryzas Z, Papadopoulou-Mourkidou E. Effect of specific plant-growth-promoting rhizobacteria (PGPR) on growth and uptake of neonicotinoid insecticide thiamethoxam in corn (Zea mays L.) seedlings. Pest Manag Sci 2015;71:1258-66. DOI PubMed

98. Flores-Céspedes F, González-Pradas E, Fernández-Pérez M, Villafranca-Sánchez M, Socías-Viciana M, Ureña-Amate MD. Effects of dissolved organic carbon on sorption and mobility of imidacloprid in soil. J Environ Qual 2002;31:880-8. DOI PubMed

99. Oi M. Time-dependent sorption of imidacloprid in two different soils. J Agric Food Chem 1999;47:327-32. DOI PubMed

100. Suchail S, Guez D, Belzunces LP. Discrepancy between acute and chronic toxicity induced by imidacloprid and its metabolites in. Apis mellifera ;20:2482-6. DOI PubMed

101. Daisley BA, Trinder M, McDowell TW, Collins SL, Sumarah MW, Reid G. Microbiota-mediated modulation of organophosphate insecticide toxicity by species-dependent interactions with lactobacilli in a drosophila melanogaster insect model. Appl Environ Microbiol 2018;84:e2820-17. DOI PubMed PMC

102. Xia X, Zheng D, Zhong H, et al. DNA sequencing reveals the midgut microbiota of diamondback moth, Plutella xylostella (L.) and a possible relationship with insecticide resistance. PLoS One 2013;8:e68852. DOI PubMed PMC

103. Lukwinski AT, Hill JE, Khachatourians GG, Hemmingsen SM, Hegedus DD. Biochemical and taxonomic characterization of bacteria associated with the crucifer root maggot (Delia radicum). Can J Microbiol 2006;52:197-208. DOI PubMed

104. Engel P, Moran NA. The gut microbiota of insects - diversity in structure and function. FEMS Microbiol Rev 2013;37:699-735. DOI PubMed

105. Almeida LG, Moraes LA, Trigo JR, Omoto C, Cônsoli FL. The gut microbiota of insecticide-resistant insects houses insecticidedegrading bacteria: a potential source for biotechnological exploitation. PLoS One 2017;12:e0174754. DOI PubMed PMC

106. French E, Kaplan I, Iyer-Pascuzzi A, Nakatsu CH, Enders L. Emerging strategies for precision microbiome management in diverse agroecosystems. Nat Plants 2021;7:256-67. DOI PubMed

107. Erler S, Denner A, Bobiş O, Forsgren E, Moritz RF. Diversity of honey stores and their impact on pathogenic bacteria of the honeybee, Apis mellifera. Ecol Evol 2014;4:3960-7. DOI PubMed PMC

108. Blacquière T, Smagghe G, van Gestel CA, Mommaerts V. Neonicotinoids in bees: a review on concentrations, side-effects and risk assessment. Ecotoxicology 2012;21:973-92. DOI PubMed PMC

109. Cullen MG, Thompson LJ, Carolan JC, Stout JC, Stanley DA. Fungicides, herbicides and bees: a systematic review of existing research and methods. PLoS One 2019;14:e0225743. DOI PubMed PMC

110. Martinson VG, Danforth BN, Minckley RL, Rueppell O, Tingek S, Moran NA. A simple and distinctive microbiota associated with honey bees and bumble bees. Mol Ecol 2011;20:619-28. DOI PubMed

111. Daisley BA, Reid G. BEExact: a metataxonomic database tool for high-resolution inference of bee-associated microbial communities. mSystems 2021;6:e00082-21. DOI PubMed PMC

112. Kwong WK, Medina LA, Koch H, et al. Dynamic microbiome evolution in social bees. Sci Adv 2017;3:e1600513. DOI PubMed $\mathrm{PMC}$

113. Kwong WK, Moran NA. Gut microbial communities of social bees. Nat Rev Microbiol 2016;14:374-84. DOI PubMed PMC

114. Jones JC, Fruciano C, Marchant J, et al. The gut microbiome is associated with behavioural task in honey bees. Insectes Soc 2018;65:419-29. DOI PubMed PMC

115. Liberti J, Engel P. The gut microbiota - brain axis of insects. Curr Opin Insect Sci 2020;39:6-13. DOI PubMed

116. Koch H, Brown MJ, Stevenson PC. The role of disease in bee foraging ecology. Curr Opin Insect Sci 2017;21:60-7. DOI PubMed

117. Decourtye A, Lacassie E, Pham-Delègue MH. Learning performances of honeybees (Apis mellifera L) are differentially affected by imidacloprid according to the season. Pest Manag Sci 2003;59:269-78. DOI PubMed

118. Kešnerová L, Emery O, Troilo M, Liberti J, Erkosar B, Engel P. Gut microbiota structure differs between honeybees in winter and summer. ISME J 2020;14:801-14. DOI PubMed PMC

119. Chmiel JA, Daisley BA, Pitek AP, Thompson GJ, Reid G. Understanding the effects of sublethal pesticide exposure on honey bees: a role for probiotics as mediators of environmental stress. Front Ecol Evol 2020;8:22. DOI

120. Robinson GE. Regulation of division of labor in insect societies. Annu Rev Entomol 1992;37:637-65. DOI PubMed

121. Nouvian M, Reinhard J, Giurfa M. The defensive response of the honeybee Apis mellifera. J Exp Biol 2016;219:3505-17. DOI PubMed

122. Martin CR, Osadchiy V, Kalani A, Mayer EA. The brain-gut-microbiome axis. Cell Mol Gastroenterol Hepatol 2018;6:133-48. DOI PubMed PMC 
123. Brauner A, Fridman O, Gefen O, Balaban NQ. Distinguishing between resistance, tolerance and persistence to antibiotic treatment. Nat Rev Microbiol 2016;14:320-30. DOI PubMed

124. Ramakrishnan B, Venkateswarlu K, Sethunathan N, Megharaj M. Local applications but global implications: can pesticides drive microorganisms to develop antimicrobial resistance? Sci Total Environ 2019;654:177-89. DOI PubMed

125. Blanco P, Hernando-Amado S, Reales-Calderon JA, et al. Bacterial multidrug efflux pumps: much more than antibiotic resistance determinants. Microorganisms 2016;4:14. DOI PubMed PMC

126. Kurenbach B, Marjoshi D, Amábile-Cuevas CF, et al. Sublethal exposure to commercial formulations of the herbicides dicamba, 2,4dichlorophenoxyacetic acid, and glyphosate cause changes in antibiotic susceptibility in Escherichia coli and Salmonella enterica serovar Typhimurium. mBio 2015;6:e0009-15. DOI PubMed PMC

127. Fraise AP. Biocide abuse and antimicrobial resistance--a cause for concern? J Antimicrob Chemother 2002;49:11-2. DOI PubMed

128. Xing Y, Wu S, Men Y. Exposure to environmental levels of pesticides stimulates and diversifies evolution in Escherichia coli toward higher antibiotic resistance. Environ Sci Technol 2020;54:8770-8. DOI PubMed

129. Rangasamy K, Athiappan M, Devarajan N, Parray JA. Emergence of multi drug resistance among soil bacteria exposing to insecticides. Microb Pathog 2017;105:153-65. DOI PubMed

130. Harper LL, McDaniel CS, Miller CE, Wild JR. Dissimilar plasmids isolated from Pseudomonas diminuta MG and a Flavobacterium sp. (ATCC 27551) contain identical opd genes. Appl Environ Microbiol 1988;54:2586-9. DOI PubMed PMC

131. Horne I, Sutherland TD, Harcourt RL, Russell RJ, Oakeshott JG. Identification of an opd (organophosphate degradation) gene in an Agrobacterium isolate. Appl Environ Microbiol 2002;68:3371-6. DOI PubMed PMC

132. Mulbry WW, Karns JS. Parathion hydrolase specified by the Flavobacterium opd gene: relationship between the gene and protein. $J$ Bacteriol 1989;171:6740-6. DOI PubMed PMC

133. Singh BK. Organophosphorus-degrading bacteria: ecology and industrial applications. Nat Rev Microbiol 2009;7:156-64. DOI PubMed

134. Utembe W, Kamng'ona AW. Gut microbiota-mediated pesticide toxicity in humans: Methodological issues and challenges in the risk assessment of pesticides. Chemosphere 2021;271:129817. DOI PubMed

135. McDonald JA, Schroeter K, Fuentes S, et al. Evaluation of microbial community reproducibility, stability and composition in a human distal gut chemostat model. J Microbiol Methods 2013;95:167-74. DOI PubMed

136. . Van de Wiele T, Van den Abbeele P, Ossieur W, Possemiers S, Marzorati M. The Simulator of the Human Intestinal Microbial Ecosystem (SHIME®). In: Verhoeckx K, Cotter P, López-expósito I, Kleiveland C, Lea T, Mackie A, Requena T, Swiatecka D, Wichers H, editors. The Impact of Food Bioactives on Health. Cham: Springer International Publishing; 2015. p. 305-17. DOI

137. Daisley BA, Chanyi RM, Abdur-Rashid K, et al. Abiraterone acetate preferentially enriches for the gut commensal Akkermansia muciniphila in castrate-resistant prostate cancer patients. Nat Commun 2020;11:4822. DOI PubMed PMC 